\title{
NARRATIVAS SOBRE A CONSTRUÇÃO DO TEMPO INTEGRAL EM ANGRA DOS REIS
}

\author{
MARCIO BERNARDINO SIRINO ${ }^{1}$
}

\begin{abstract}
RESUMO: Este presente trabalho - recorte da pesquisa de Mestrado em Educação, defendida no Programa de Pós-Graduação em Educação da Universidade Federal do Estado do Rio de Janeiro (PPGEdu/UNIRIO) - visa apresentar o processo de materialização da política pública de educação em tempo integral do município de Angra dos Reis (RJ), tendo a clareza de que a socialização dessa experiência política, em construção desde 2009, muito pode contribuir para a problematização no que tange às Políticas Públicas Educacionais. Para essa finalidade, foi utilizada, como aporte metodológico, a análise documental em articulação com a pesquisa bibliográfica de autores que abordam a temática da Educação Integral em Tempo Integral e, ainda, da própria política pública educacional como uma forma de percebermos que a política pública se ressignifica na prática e adquire novas dimensões por conta do ciclo pelo qual passa.

Palavras-chave: Educação em Tempo Integral. Gestão e Avaliação em Educação. Políticas Públicas Educacionais.
\end{abstract}

\section{NARRATIVES ON THE CONSTRUCTION OF THE INTEGRAL TIME IN ANGRA DOS REIS}

ABSTRACT: This present work - cut of the research of Master in Education, defended in the Graduate Program in Education of the Federal University of the State of Rio de Janeiro (PPGEdu / UNIRIO) - aims to present the process of materialization of public education policy in time in the city of Angra dos Reis (RJ), with the clarity that the socialization of this political experience, under construction since 2009, can greatly contribute to the problematization of Public Educational Policies. For this purpose, was used - as a methodological contribution the documentary analysis in articulation with the bibliographical research of authors that approach the theme of Integral Education in Integral Time and also of the public educational policy itself as a way of perceiving that public policy is reaffirmed in practice and acquires new dimensions on account the cycle through which it passes.

Keywords: Integral Time Education. Management and Evaluation in Education. Public Educational Policies.

1 Mestre em Educação (PPGEdu/UNIRIO). Servidor Público da Prefeitura Municipal de Angra dos Reis (PMAR). Membro do Núcleo de Estudos - Tempos, Espaços e Educação Integral (NEEPHI/UNIRIO). 


\section{NARRATIVAS SOBRE LA CONSTRUCCIÓN DEL TIEMPO INTEGRAL EN ANGRA DOS REIS}

RESUMEN: Este trabajo - recorte de la investigación de Maestría en Educación, defendida en el Programa de Postgrado en Educación de la Universidad Federal del Estado de Río de Janeiro (PPGEdu / UNIRIO, se propone presentar el proceso de materialización de la política pública de educación a tiempo completo del municipio de Angra dos Reis (RJ) teniendo la claridad de que la socialización de esa experiencia política, en construcción desde 2009, puede contribuir a la problematización en lo que se refiere a las Políticas Públicas Educativas. Para este propósito, fue utilizado como aporte metodológico el análisis documental en articulación con la investigación bibliográfica de autores que abordan la temática de la Educación Integral en Tiempo Integral y además, de la propia política pública educativa como una forma de percibir que la política pública se resignifica en la práctica y adquiere nuevas dimensiones por cuenta del ciclo por el cual pasa.

Palabras clave: Educación en Tiempo Completo. Gestión y Evaluación en Educación. Políticas Públicas Educativas.

\section{Introdução}

A temática da educação em tempo integral - por vezes, nomeada como 'educação integral' - vem sendo potencializada, nos últimos anos, em todo o território nacional. Certamente, essa discussão não é recente, mas - a partir do ano de 2007, data em que foi criado o Programa Mais Educação (PME)², a mesma veio alcançando diversos estados e municípios brasileiros ao propor a ampliação da jornada escolar dos educandos na perspectiva de uma educação integral.

Nesse sentido, diferenciadas propostas políticas vêm sendo construídas, no bojo da educação integral e $(\mathrm{m})$ tempo integral, e múltiplas práticas educativas sendo experienciadas em sentido restrito e amplo, como nos pontua Leclerc e Moll (2012).

Em sentido restrito refere-se à organização escolar na qual o tempo de permanência dos estudantes se amplia para além do turno escolar, também denominada, em alguns países, como jornada escolar completa. Em sentido amplo, abrange o debate da educação integral - consideradas as necessidades formativas nos campos cognitivo, estético, ético, lúdico, físicomotor, espiritual, entre outros - no qual a categoria "tempo escolar" revestese de relevante significado tanto em relação a sua ampliação, quanto em relação à necessidade de sua reinvenção no cotidiano escolar (p. 96).

${ }^{2}$ O Programa Mais Educação (PME) - instituído pela Portaria Interministerial no 17/2007 e pelo Decreto $\mathrm{n}^{\circ} 7.083$, de 27 de janeiro de 2010 - integra as ações do Plano de Desenvolvimento da Educação (PDE), como uma estratégia do Governo Federal para induzir a ampliação da jornada escolar e a organização curricular, na perspectiva da Educação Integral. 
Esse feito nos possibilita refletir que diferentes decisões políticas se desdobram, por sua vez, em políticas públicas específicas, levando em consideração a 'arena de disputas' que encontramos no processo da construção dessas ações por parte do poder público (RUA, 1998).

Com essa certeza, trazemos, neste presente artigo, o relato do processo de construção da política pública de educação em tempo integral no município de Angra dos Reis (RJ) - parte integrante da pesquisa de Mestrado em Educação defendida, no ano de 2017, pelo Programa de Pós-Graduação em Educação, na Universidade Federal do Estado do Rio de Janeiro - PPGEdu/UNIRIO.

A referida pesquisa, intitulada "A trajetória da Educação em Tempo Integral na Rede Municipal de Ensino de Angra dos Reis (RJ): uma composição entre o universal e o focal?" - embora traga, em seu bojo, a discussão de duas políticas de educação em tempo integral, a saber: a política federal (Programa Mais Educação) e a política municipal (Centros de Educação e Horário Integral), neste artigo, primamos por apresentar as especificidades da política municipal - uma vez que a mesma, ao longo dos anos, foi se ressignificando e se consolidando enquanto a busca pela ampliação da jornada escolar dos educandos - das 4 (quatro) unidades escolares municipais de educação em tempo integral existentes - para uma educação em tempo integral e, ainda, para o desenvolvimento de uma formação humana mais completa (COELHO, 2009), que abarque as diferentes dimensões formadoras (GUARÁ, 2006) aos sujeitos inseridos neste processo, muito embora, segundo Coelho (2009), "não há hegemonia no tocante ao que se convenciona chamar de 'formação completa', ou seja, quais pressupostos teóricos e abordagens metodológicas a constituirão" (p. 90).

Para essa finalidade, convém pontuar que nos embasamos metodologicamente na análise documental - aportes que registram e normatizam a política municipal - em diálogo com referenciais bibliográficos que argumentam acerca da temática que constitui este artigo, elaborado enquanto narrativa por acreditarmos que se fazem necessárias outras formas de expressão, na produção acadêmica, conforme aponta Oliveira (2010). Desse modo, trazemos, na sequência, uma problematização, inicial, sobre os conceitos de educação em tempo integral e de educação integral, uma vez que esta discussão se constitui elemento singular desta produção. 


\section{Uma discussão conceitual sobre educação em tempo integral e educação integral}

A carga horária regular dos sistemas de ensino se pauta em torno de 4 h diárias. No entanto, com a orientação para a 'progressiva ampliação' da jornada escolar (BRASIL, 1996), algumas unidades escolares passaram a aumentar a carga horária diária para 5 ou 6 horas, o que as faz se inserir na perspectiva de jornada ampliada. Entretanto, no que se refere à educação em tempo integral destacamos, com base na Meta 6 do atual Plano Nacional de Educação (2014-2024), que se considera como sendo aquela jornada escolar que abranja um período "igual ou superior a 7 (sete) horas diárias durante todo o ano letivo" (BRASIL, 2014).

A ideia da educação em tempo integral, com a ampliação da jornada escolar para, no mínimo, 7h diárias se pauta na necessidade de se promover maiores oportunidades de aprendizagem aos educandos das classes populares na perspectiva da educação integral, de forma a articular estes dois conceitos.

É importante dizer que falar sobre educação integral, para nós, pressupõe falar, também, em tempo ampliado/integral na escola: com o tempo escolar ampliado, é possível pensar em uma educação que englobe formação e informação e que compreenda outras atividades - não somente as conhecidas como atividades escolares - para a construção da cidadania partícipe e responsável (COELHO, 2009, p. 93).

Essa compreensão se fundamenta no entendimento de que aumentando o tempo do educando, consequentemente, amplia-se a sua formação. E, por tratar de formação, faz-se necessário problematizar a visão de educação que se tem com o aumento da carga horária proposta para os alunos, uma vez que não se pode ampliar o tempo do educando na escola para se ofertar "mais do mesmo", como nos sinaliza Paro (2009), mas sim para estruturar um cotidiano de vivências significativas e de aprendizagens em todas as diferentes dimensões formadoras do sujeito, o que nos faz dialogar com os pressupostos de uma educação integral.

Embora possamos inferir que a educação integral se configure numa arena de disputa (RUA, 1998) por ser um conceito em construção (CAVALIERE, 2009), no geral, a partir das contribuições de Coelho $(2009$, p. 90) se entende educação integral como sendo "a busca pela formação humana mais completa possível para o ser humano". Desse modo, tendo iniciado uma discussão acerca desses conceitos basilares de nosso artigo, trazemos, na sequência, um pouco da história da política municipal de educação em tempo integral de Angra dos Reis (RJ) com as particularidades a ela inerentes. 


\section{Era uma vez os CEHIs}

A pesquisa de mestrado, com base em toda discussão teórica e conceitual, realização de entrevistas estruturadas e análise de conteúdo, possibilitou o conhecimento mais ampliado acerca da trajetória da educação em tempo integral na rede municipal de ensino de Angra dos Reis, principalmente, no que tange à política municipal. Sendo assim, tirando a estrutura mais 'formatada', da dissertação, trazemos neste artigo uma 'outra escrita' na qual narramos o processo de construção e de atualização da política municipal de educação em tempo integral.

No ano de 2008, estava à frente da gestão pública municipal o prefeito Fernando Jordão. Pesquisas revelavam que, com o término de seu mandato, o prefeito Tuca Jordão assumiria, dando continuidade, desse modo, à gestão do PMDB no município de Angra dos Reis.

Convém destacar que, com a criação do Programa Mais Educação (BRASIL, 2007), o grupo que vinha se reunindo para dialogar acerca das propostas de campanha para Tuca Jordão identificou, na política de educação em tempo integral, a possibilidade de vir a ser o "carro-chefe" do governo e, ainda, angariar verba para o município com os aportes financeiros desse Programa Federal. Nesse contexto, tão logo assumiu o poder, em 2009, um grupo de coordenadores foi formado para dar continuidade à proposta e materializar, assim, a educação em tempo integral na rede municipal de ensino de Angra dos Reis.

O projeto de criação dos Centros de Educação e Horário Integral (CEHIs) aponta para a realização de assessoria pedagógica com a professora Dr. Carmem Rangel, da Fundação Darcy Ribeiro (FUNDAR), a qual esteve presente no município levando textos, discussões e oportunizando espaços de formação sobre a construção de uma escola de educação em tempo integral que, por sua vez, primava pela formação integral dos educandos. Tendo passado alguns meses de diálogos e reflexões, os Centros de Educação e Horário Integral foram criados pela Resolução n. 005/2009 e, a partir de então, implantados os seguintes CEHIs.

- 2009 - CEHI Benedito dos Santos Barbosa (Monsuaba);

- 2010 - CEHI Monsenhor Pinto de Carvalho (Ilha Grande);

- 2010 - CEHI Maria Hercília Cardoso de Castro (Vila Velha);

- 2011 - CEHI João Carolino dos Remédios (Mo da Glória II).

Como podemos observar, a implementação dos CEHIs ocorreu de maneira gradativa, em 4 
unidades escolares que atendem, em média, anualmente, 450 alunos da educação infantil aos anos iniciais do ensino fundamental (1으 ao 5 ano de escolaridade). Percebamos que, nessas unidades escolares, não se contempla os alunos dos anos finais do ensino fundamental (6 ao 9 o ano de escolaridade). Nesse contexto, faz-se necessário pontuar, a título de melhor compreensão da dinâmica desenvolvida nessas unidades escolares, que cada turma possuía um professor regente (Docente I) responsável pelos componentes curriculares da Base Nacional Comum e, ainda, por Oficinas Pedagógicas elegidas em articulação com o Projeto Político-Pedagógico (PPP) de cada CEHI, bem como do Projeto de Trabalho para o ano letivo em vigor.

Havia, também, no cotidiano escolar do CEHI, a oferta de Oficinas Pedagógicas de Arte, Educação Física e Educação Ambiental - ministradas por professores especialistas (Docente II) e, ainda, a inserção de oficinas do Programa Mais Educação que são escolhidas de acordo com os 'macrocampos'3 propostos pelo programa.

Entende-se por Oficina Pedagógica um espaço de ampliação das oportunidades de aprendizagem, onde as ações educativas dialoguem com os componentes curriculares da Base Nacional Comum, através de atividades lúdicas, dinâmicas e integradas a serem realizadas por todos os alunos, na própria unidade escolar ou fora dela (ANGRA DOS REIS, 2016, p. 3).

Assim que iniciou a ampliação da jornada escolar dos educandos dessas unidades escolares, a carga horária diária foi modificada para $8 \mathrm{~h} 30 \mathrm{~min}$ por dia. Sendo, apenas, para a escola localizada na Ilha Grande - por conta da logística do barco - a carga horária de 8h. Nesse tempo integral, os alunos passavam, como vimos nos parágrafos anteriores, por diferentes Oficinas Pedagógicas como estratégia para a ampliação das oportunidades de aprendizagem dos educandos na compreensão de que diferentes linguagens, desenvolvidas por múltiplos educadores, muito contribui para a formação humana mais completa dos alunos, ou seja, a educação integral.

Trazemos, nesse bojo, as contribuições de Souza (2016) que associa o conceito de formação humana a um 'ideal' de formação, a saber:

3 Na sequência, destacamos os ‘macrocampos’ propostos pelo Programa Mais Educação (PME): acompanhamento pedagógico; educação ambiental; esporte e lazer; direitos humanos em educação; cultura e artes; cultura digital; promoção da saúde; comunicação e uso de mídias; investigação no campo das ciências da natureza e educação econômica. Disponível em:<http://portal.mec.gov.br/programa-mais-educacao>. Acesso em: 12 mar. 2017. 
Pensar formação humana remete a voltar olhares para muitos séculos atrás. Quando as sociedades, em seus diferentes períodos e vivências, refletiram sobre a formação do ser humano, pensaram no ideal desta formação. A arete grega, o homem da democracia ateniense, o guerreiro espartano, o reifilósofo e os guardiões de Platão, o clérigo e a nobreza do período feudal e o virtuoso homem de negócios iniciado no liberalismo (e vividos até os dias de hoje) são provas disso. Ideais de formação humana que correspondem aos anseios sociais, ou melhor, de uma parcela da sociedade, para as vivências de seus respectivos períodos históricos (SOUZA, 2016, p. 68-69).

Percebamos que esse 'ideal de formação' apresentado por Souza (2016) dialoga com as contribuições de Saviani e Duarte (2010), ao afirmar que "a formação humana é analisada na relação entre o processo histórico de objetivação do gênero humano e a vida do indivíduo como um ser social" (p. 426), ou seja, a educação integral e(m) tempo integral, dentro de uma perspectiva históricoontológica, tem o potencial de contribuir para a formação humana mais completa dos educandos.

Dando continuidade a nossa narrativa, percebemos que, com o objetivo de oferecer espaços promotores de aprendizagem e que contribuíssem para essa 'formação humana', os CEHIs faziam uso, constante, de bibliotecas, salas de vídeo, pátios, laboratórios de informática e, ainda, brinquedotecas - espaços estes diferenciados que se constituíam enquanto territórios educativos.

É necessário tempo de permanência na escola para que a criança das classes populares tenha igualdade de oportunidade que as crianças de classe média têm, em espaços variados e ao longo do dia inteiro, com acesso a linguagens e circunstâncias diversas. É necessário tempo para adquirir hábitos, valores, conhecimentos para o exercício da cidadania numa sociedade complexa como a brasileira do século XXI (MAURícIO, 2009, p. 55).

Outra especificidade que se faz necessário destacar se relaciona com a alimentação dos educandos. Ao longo do dia, os alunos recebiam quatro refeições equilibradas e elaboradas por nutricionistas da rede, a saber: desjejum; colação; almoço com suco e sobremesa e, por fim, lanche da tarde - um olhar, efetivamente, integral acerca do desenvolvimento dos educandos inseridos nos CEHIs.

E, por tratar de 'olhar integral', cabe pontuar a preocupação com a organização pedagógica dessas unidades escolares. Fundamentados na Pedagogia de Projetos, os CEHIs desenvolviam ações integradas entre todas as áreas do conhecimento e oficinas pedagógicas e, ainda, possuíam uma avaliação mais holística na medida em que diferentes educadores avaliavam os educandos, ou seja, os alunos não eram avaliados por uma área de conhecimento, habilidade ou pela dimensão cognitiva, apenas. Mas, sim, pela integralidade que habita em cada educando, como podemos observar nas 
contribuições de Hoffman (2005) acerca da avaliação numa perspectiva que transforma a reflexão em ação.

\begin{abstract}
A avaliação é reflexão transformada em ação. Ação, essa que nos impulsiona a novas reflexões. Reflexão permanente do educador sobre sua realidade, e acompanhamento de todos os passos do educando na sua trajetória de construção de conhecimento. Um processo interativo, através do qual educandos e educadores aprendem sobre si mesmos e sobre a realidade escolar no ato próprio da avaliação (HOFFMAN, 2005 p. 17).
\end{abstract}

Logo, todos os educadores avaliavam o desenvolvimento humano mais completo de todos os alunos e, juntos, construíam ações pedagógicas para diminuir as dificuldades de aprendizagem apresentadas.

Muitas ações foram desenvolvidas, ao longo da gestão de Tuca Jordão: Seminários Internos; Formações com as equipes técnico-pedagógicas e, ainda, a realização do I Seminário de Educação Integral de Angra dos Reis, momentos significativos para a reflexão da prática pedagógica desenvolvida e para a fundamentação teórica da política de educação em tempo integral, em construção.

\title{
Eis que a política se reconstrói
}

Como observamos na seção anterior, durante os anos de 2009 a 2012, houve a gestão de Tuca Jordão e foi dado início à materialização da política municipal de educação em tempo integral em Angra dos Reis, no entanto, no ano de 2013, eis que a gestão do PMDB se finda, em Angra dos Reis, e Conceição Rabha, do Partido dos Trabalhadores (PT) assume à prefeitura. Sua gestão foi conquistada por meio de muitas contrapartidas e filiações, o que não possibilitou atuar conforme se propusera nem como os angrenses esperavam.

Foi uma gestão de muitos cortes e de muitas dificuldades para a construção/ampliação de qualquer proposta, inclusive de educação em tempo integral que, diretamente, impactava na folha de pagamento, na oferta de maiores materiais pedagógicos às unidades escolares, na alimentação dobrada aos educandos, dentre muitas outras necessidades correlatas. Enfim, tudo ampliado, uma vez que os alunos passam, praticamente, o dobro do tempo na escola.

No entanto, nessa maré de cortes e de dificuldades financeiras atrelada, inclusive, à crise econômica pela qual o país veio atravessando, podemos pontuar que, no ano de 2014, houve a tentativa de dialogar sobre a política municipal de educação em tempo integral no interior da 
Secretaria Municipal de Educação, Ciência e Tecnologia (SECT). Sendo assim, começava-se um processo de modificação da Resolução que tinha criado os CEHIs.

Convém sinalizar que a perspectiva de atualização dessa Resolução estava relacionada com a carga horária em defasagem que a mesma trazia e a necessidade de se estabelecer alguns acordos no corpo da lei para garantir melhores condições de trabalho e a oferta de uma educação em tempo integral de qualidade. Então, no ano de 2013, a 'casa' foi sendo arrumada a partir da nova gestão que se iniciava e, em 2014, foi dado início ao processo de atualização da resolução dos CEHIs. Para essa finalidade, diversas reuniões foram realizadas, tanto no interior da SECT quanto nas unidades escolares, além de espaços de formação e de discussão com os educadores dos CEHIs.

Nessa perspectiva, destacamos o evento "Troca de Saberes e Fazeres" no qual cada CEHI sediava, numa data específica o evento, e apresentava para as outras unidades escolares de educação em tempo integral, sua pedagogia, seus projetos e suas especificidades - momento muito rico de socialização de conhecimentos bem como da construção de uma 'Unidade na Diversidade' de práticas pedagógicas na política municipal de educação em tempo integral no município de Angra dos Reis. 0 tempo foi passando e, no ano de 2015, com a orientação para que os estados e municípios realizassem os devidos alinhamentos de seus Planos Municipais de Educação ao Plano Nacional de Educação (20142024), Angra dos Reis, no bojo da meta 6, referente à educação em tempo integral, fez toda uma discussão que culminou na publicação da seguinte meta:

Oferecer educação em tempo integral para, no mínimo 50\% (cinquenta por cento) das escolas de anos iniciais do ensino fundamental prioritariamente, e, no mínimo, $25 \%$ das escolas de anos finais do município, de forma a atender, pelo menos, 50\% (cinquenta por cento) dos alunos da Educação Básica até o fim da vigência deste Plano (ANGRA DOS REIS, 2015, p. 21).

Percebamos que a meta acima difere da meta do PNE, uma vez que esta em destaque sinaliza, especificamente, um percentual a ser alcançado para escolas do ensino fundamental em maioria de anos iniciais em detrimento de anos finais, o que nos faz inferir `a estratégica perspectiva de atuação. Pois, no campo da educação básica, as unidades de ensino médio são contempladas pelo Estado, assim como parte dos anos finais do ensino fundamental. No entanto, os anos iniciais ficam a cargo, exclusivo, do município e, devido ao quantitativo enorme de alunos inseridos nesta etapa de ensino, justifica-se a perspectiva de maior oferta da educação em tempo integral para o atendimento a estes educandos. 


\section{A política que vai se ressignificando e tomando novas configurações no município de Angra dos Reis}

Embora a discussão sobre a atualização da resolução de criação dos CEHIs tivesse começado em 2014, apenas dois anos depois, houve a aprovação da Resolução n. 003/2016 - trazendo em seu bojo a correção da carga horária, a modificação da mesma e ainda, algumas especificidades necessárias - solicitadas pelos educadores, a saber: articulação pedagógica; matriz curricular; inserção das competências dos sujeitos inseridos neste cotidiano, dentre outros apontamentos significativos.

$\mathrm{Na}$ antiga Resolução, a carga horária dos alunos estava equivocada (1200h anuais), uma vez que os educandos permaneciam numa carga horária de 8h30min diárias. Nessa Resolução atual, a carga horária foi atualizada para 7h diárias para os alunos (1400h anuais, durante os 200 dias letivos) e, ainda, houve a modificação na nomenclatura da política municipal.

De Centros de Educação e Horário Integral (CEHIs) as unidades escolares passaram a ser denominadas como Centros de Educação em Tempo Integral (CETIs), uma mudança singela, mas que revela uma discussão conceitual importante uma vez que a dimensão 'horário' denota uma compreensão mais 'quantitativa' da ampliação da jornada escolar, enquanto o termo 'tempo' apresenta uma perspectiva mais 'qualitativa' da mesma. Junto a essa modificação veio a perspectiva de implantação de novos CETIs de maneira gradativa, bem como o público-alvo a ser atendido nas escolas de educação em tempo integral, a saber: alunos da educação infantil e dos anos iniciais do ensino fundamental, numa carga horária de 7h diárias. Um destaque necessário que essa resolução apresenta está relacionado com a organização do currículo por meio dos componentes curriculares da BNCC em articulação com as oficinas pedagógicas ofertadas.

No que tange às oficinas, a resolução delimita 3 (três) oficinas pedagógicas de professores especialistas (Docentes II), como podemos observar na Figura 1 referente à matriz curricular para as escolas de educação em tempo integral da rede municipal de ensino de Angra dos Reis. 


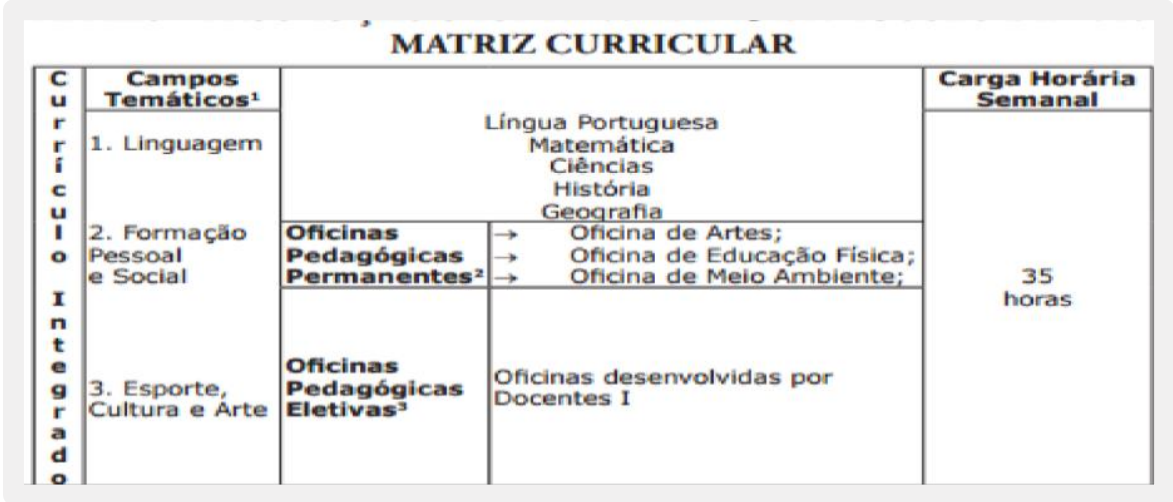

Figura 1 - Matriz Curricular

Fonte: Angra dos Reis, 2016

Percebamos que a matriz curricular foi elaborada com base em 3 (três) campos temáticos Linguagem; Formação Pessoal e Social; Esporte, Cultura e Arte que, por sua vez, aglutinam os componentes curriculares obrigatórios e, na parte diversificada do currículo, as oficinas pedagógicas permanentes e as oficinas pedagógicas eletivas perfazendo, todos, uma carga horária semanal de 35 horas. Destacamos que cada componente dessa matriz possui dois tempos/aula com duração de 50 minutos. E, após a saída dos educandos, acontece o horário de coordenação pedagógica composto por $2 \mathrm{~h}$ diárias para os professores.

Uma demarcação importante a sinalizar é a vinculação da prática pedagógica, desenvolvida nos CETIs, em articulação com os Princípios Norteadores da Educação de Angra dos Reis (Educação Inclusiva, Gestão Democrática e Qualidade do Ensino) elaborados para a gestão 2013/2016. Outro dado significativo que a Resolução veio a 'amarrar' se deu com relação às competências dos diferentes atores que fazem parte dessa política municipal, a saber:

Competências da SECT: formação continuada, espaços de discussão e reuniões sistemáticas.

Competências das Equipes Técnico-Pedagógicas dos CETls: formação continuada, elaboração de PPP, cumprimento da carga horária dos alunos, inclusão dos alunos, construção de projeto de trabalho, mediação de conflitos e demais tarefas referentes à organização do cotidiano escolar.

Competência dos professores-docentes: ministrar aulas e efetuar os devidos registros (ANGRA DOS REIS, 2016, p. 3).

Por fim, salientamos os pré-requisitos com relação aos profissionais que atuarão nos CETls:

Atender às características e especificidades de Educação Integral em Tempo Integral; ter disponibilidade, no caso do docente I, em desenvolver as suas atividades em período integral na unidade escolar;

Ter postura democrática e disponibilidade para o desenvolvimento de 
trabalho em equipe, de forma colaborativa;

Ser assíduo e pontual;

Promover a autoestima do educando e a formação de valores;

Participar de programas de capacitação e formação continuada;

Posicionar-se como pesquisador a fim de aprimorar a prática pedagógica desenvolvida (ANGRA DOS REIS, 2016, p. 3).

Todas essas atribuições contribuem para a percepção do perfil dos educadores que devem atuar nos Centros de Educação em Tempo Integral - um perfil mais humanizador e disposto para a construção de práticas pedagógicas coletivas e que não nega o outro nem promove processos de exclusão no interior das unidades escolares, como nos pontua Graciani (2011).

A negação do outro, diferente de mim, tem sido considerada, no mundo contemporâneo, um dos piores fatores geradores de conflitos sociais, dissabores pessoais, revoltas e agressões, entre outros. A invisibilidade do outro que está ao meu lado é um dos componentes do processo da exclusão, seja ela causada por preconceito étnico, cultural, religioso, por discriminação de gênero, opção sexual ou desigualdade social (p. 96).

\section{Sinais de reflexão em tempos de conclusão}

Faz-se necessário sinalizar, neste desfecho, a importância do processo de discussão e de ressignificação desta política pública municipal de educação em tempo integral. Pois, a política pública é uma "arena de disputas", como afirma Rua (1998), envolvendo decisão política, escolhas e mediação de interesses cruzados. Nessa certeza, pontuamos que a implantação das políticas públicas se configura num 'processo de relações', que dialoga, diretamente, com o 'ciclo de políticas de Ball', conforme o sintetizamos, no recuo abaixo:

Contexto de influência: onde normalmente as políticas públicas são iniciadas e os discursos políticos são construídos.

Contexto da produção de texto: onde se produz os textos políticos que, por sua vez, representa a política.

Contexto da prática: onde a política está sujeita à interpretação e recriação e onde a política produz efeitos e consequências que podem representar mudanças e transformações significativas na política original.

Contexto dos resultados/efeitos: onde se preocupa com questões de justiça, igualdade e liberdade individual.

Contexto de estratégia política: onde se envolve a identificação de um conjunto de atividades sociais e políticas que seriam necessárias para lidar com as desigualdades criadas ou reproduzidas pela política investigada (MAINARDES, 2006, p. 50-55). 
Principalmente, quando dentre os seus contextos sobressai o 'contexto da prática' como sendo o lócus de reinterpretação e de significativa transformação da política original (MAINARDES, 2006). Desse modo, convém afirmar que apresentar as especificidades dessa política pública de educação em tempo integral, do município de Angra dos Reis, oportuniza-nos a problematização acerca da gestão de políticas públicas e, ainda, a avaliação do impacto das mesmas no cenário educacional.

Essas 'idas e vindas', infindos processos de atualização, construção e de (re)construção, assim como a necessidades de adequação, em tempos de cortes, escassez financeira e de crise econômica, nos certifica de que, atrelada a uma decisão política, as ações do poder público vão se materializando bem como se ressignificando, a cada dia, no contexto da prática - consolidando, assim, uma educação em tempo integral em permanente devir - ou seja, transformação.

\section{Referências}

ANGRA DOS REIS. Resolução Municipal SECT n. 005 de 16 de julho de 2009. Dispõe sobre a criação e o funcionamento dos Centros de Educação e Horário Integral de Angra dos Reis. Boletim Oficial do Município de Angra dos Reis, RJ, 20 ago. 2009.

. Princípios norteadores da Educação de Angra dos Reis. Angra dos Reis: Secretaria Municipal de Educação, Ciência e Tecnologia, 2013.

. Lei n. 3.357, de 02 de julho de 2015. Aprova o Plano Municipal de Educação de Angra dos Reis. Boletim Oficial do Município de Angra dos Reis, RJ, 03 jul. 2015.

Resolução Municipal SECT n. 003 de 25 de agosto de 2016. Dispõe sobre a alteração da Resolução SECT n. 005 de 16 de julho de 2009, regulamenta o funcionamento das escolas em tempo integral da Rede Municipal de Ensino de Angra dos Reis e dá outras providências. Boletim Oficial do Município de Angra dos Reis, RJ, 02 set. 2016.

BRASIL. Lei n. 9.394, de dezembro de 1996. Dispõe sobre as diretrizes e bases da educação nacional. Diário Oficial da União, Brasília, DF, 23 dez. 1996.

. Emenda Constitucional n. 53, de 19 de dezembro de 2006. Cria o Fundo de Manutenção e Desenvolvimento da Educação Básica e de Valorização dos Profissionais da Educação - FUNDEB. Diário Oficial da União, Brasília, DF, 20 dez. 2006.

. Portaria Interministerial n. 17, de 24 de abril de 2007. Diário Oficial da União, Brasília, DF, 26 abr. 2007.

. Decreto no. 7.083, de 27 de janeiro de 2010. Dispõe sobre o Programa Mais Educação. Diário Oficial da União, Brasília, DF, 27 jan. 2010.

. Lei n. 13.005, de 24 de junho de 2014. Aprova o Plano Nacional de Educação. Diário Oficial da União, Brasília, DF, 26 jun. 2014. 
CAVALIERE, A. M. Conceito de educação integral é um conceito em construção. Jornal do professor. Rio de Janeiro, 27 mai. $2009 . \quad$ Disponível em: http://portaldoprofessor.mec.gov.br/noticias.html?idEdicao=21\&idCategoria=8>. Acesso em: 23 fev. 2016.

COELHO, L. M. C. C. História(s) da educação integral. Brasília: Em Aberto, v. 22, n. 80, p. 83-96, abr. 2009.

GUARÁ, I. M. F. R. É imprescindível educar integralmente. Cadernos CENPEC, São Paulo, n. 2, p. 15-24, 2006.

GRACIANI, M. S. S. A formação do educador social e a Pedagogia da Convivência. In: RAMOS, M. F.; ROMAN, A. (Orgs.), Educadores Sociais: a importância da formação na implementação de tecnologias sociais. Brasília, DF: Fundação Banco do Brasil, 2011. p. 91-99.

HOFFMAN, J. Avaliação: mito e desafio: uma perspectiva construtivista. Porto Alegre: Mediação, 2005.

LECLERC, G. F. E.; MOLL, J. Programa Mais Educação: avanços e desafios para uma estratégia indutora da educação integral em tempo integral. Educar em Revista, Curitiba: Editora UFPR, n. 45, p. 91-110, jul./set. 2012.

MAINARDES, J. Abordagem do ciclo de políticas: uma contribuição para a análise de políticas educacionais. Educ. Soc., Campinas, v. 27, n. 94, p. 47-69, jan./abr. 2006.

MAURíCIO, L. V. Políticas públicas, tempos, escola. In: COELHO, L. M. C. C. (Org.), Educação integral em tempo integral: estudos e experiências em processo. Rio de Janeiro: FAPERJ, 2009. p. 53-68.

OLIVEIRA, I. B. (Org.). Narrativas: outros conhecimentos, outras formas de expressão. Rio de Janeiro: FAPERJ, 2010.

PARO, V. H. Educação integral em tempo integral: uma concepção de educação para a modernidade. In: COELHO, L. M. C. C. (Org.), Educação integral em tempo integral: estudos e experiências em processo. Petrópolis, RJ: FAPERJ, 2009. p. 13-20.

RUA, M. G. Análise de políticas públicas: conceitos básicos. In: RUA, M. G; CARVALHO, M. I. V. (Orgs.), O estudo da política: tópicos selecionados. Brasília: Paralelo 15, 1998. p. 231-260.

SAVIANI, D.; DUARTE, N. A formação humana na perspectiva histórico-ontológica. Revista Brasileira de Educação, v. 15, n. 45, p. 422-433, set./dez, 2010.

SOUSA, G. J. A. Educação integral: percursos e ideais sobre a formação humana. Dissertação (Mestrado em Educação), Universidade Federal do Estado do Rio de Janeiro, Rio de Janeiro, 2016.

Recebido em: 09/07/2017

Aceito em: 09/10/2017 